\title{
Trauma, attachment, and family therapy with grandfamilies: A model for treatment
}

\author{
Deena D. Strong \\ Brigham Young University - Provo \\ Roy A. Bean \\ Brigham Young University - Provo, roy_bean@byu.edu \\ Leslie L. Feinauer \\ Brigham Young University - Provo
}

Follow this and additional works at: https://scholarsarchive.byu.edu/facpub

Part of the Other Social and Behavioral Sciences Commons

\section{Original Publication Citation}

*Strong, D. D., Bean, R. A., Feinauer, L. (2010). Trauma, attachment, and family therapy with Grandfamilies: A model for treatment. Child and Youth Services Review, 32, 44-50.

\section{BYU ScholarsArchive Citation}

Strong, Deena D.; Bean, Roy A.; and Feinauer, Leslie L., "Trauma, attachment, and family therapy with grandfamilies: A model for treatment" (2009). Faculty Publications. 5056.

https://scholarsarchive.byu.edu/facpub/5056

This Peer-Reviewed Article is brought to you for free and open access by BYU ScholarsArchive. It has been accepted for inclusion in Faculty Publications by an authorized administrator of BYU ScholarsArchive. For more information, please contact ellen_amatangelo@byu.edu. 


\title{
Trauma, attachment, and family therapy with grandfamilies: A model for treatment
}

\author{
Deena D. Strong *, Roy A. Bean, Leslie L. Feinauer \\ Marriage and Family Therapy Program, School of Family Life, Brigham Young University, United States
}

\section{A R T I C L E I N F O}

\section{Article history:}

Received 5 May 2009

Received in revised form 26 June 2009

Accepted 26 June 2009

Available online 5 July 2009

\section{Keywords:}

Grandfamilies

Trauma

Attachment

Family therapy

\begin{abstract}
A B S T R A C T
Population estimates indicate that approximately 1.5 million children are in grandparent-headed households without any parents present. This type of grandfamily is often created when biological parents are unable or unwilling to care for their children. Trauma is often experienced as a precursor to, or a consequence of, the biological parents' inability or unwillingness to care for their children. The well-being of both grandparent and grandchild may be affected in grandfamilies. A treatment model is presented that integrates trauma, attachment, and family systems theories and proposes that healing is facilitated through the emerging attachment between the grandparent and grandchild.
\end{abstract}

(c) 2009 Elsevier Ltd. All rights reserved.

\section{Introduction}

The 2008 Current Population Survey has identified approximately $9 \%$ of all children ( 6.6 million) living in the United States as living in a household that includes a grandparent. Of these children, 23\% (1.5 million) had no parent present in the household (Edwards, 2009). These grandchildren and grandparents are often referred to as "custodial grandchildren" and "custodial grandparents," while their family structure is referred to as a "grandfamily" (Hayslip \& Kaminski, 2006). Although grandfamilies are created for a variety of reasons, this article focuses on grandfamilies which have been created when biological parents are unable or unwilling to care for their children, with some type of traumatic event or crisis as a common causal factor associated with this parental inability or unwillingness. The trauma, experienced at almost any level of magnitude, impacts both grandparents and grandchildren developmentally, influencing physical and emotional health and compromising the child's ability to trust his or her parents and other attachment figures. These primary relationships, when disrupted, add further clinical complications given that "the ability of children to recover from traumatic experiences is influenced by the quality of their attachments" (Busch \& Lieberman, 2007, p. 139). Consequently, it is important to acknowledge the effects of trauma and to use an integrated model of attachment and family systems theories when treating the grandchild(ren) and the custodial grandparent(s), given their unique family structure.

\footnotetext{
* Corresponding author. Department of Marriage and Family Therapy, 274 TLRB Brigham Young University, Provo, UT 84602, United States. Tel.: +1 (801) 4223888. E-mail address: deenastrong@hotmail.com (D.D. Strong).
}

The current literature relating to intervention with these families has included supporting custodial grandparents through access to community resources (e.g. Hayslip \& Shore, 2000; Whitley, White, Kelley, \& Yorke, 1999), parent training (e.g. Cox, 2000), and support groups (Strom \& Strom, 2000). Literature specifically relating to supporting custodial grandchildren has been scant with most coming from school-based interventions (e.g. Edwards \& Daire, 2006; Edwards \& Sweeney, 2007). Grandparent and grandchild relationalbased treatments are sorely lacking for this population. This paper builds on previous grandfamily literature, especially that which addresses attachment theory (Connor, 2006; Dolbin-MacNab, 2005; Edwards \& Sweeney, 2007; Poehlmann, 2003), and presents a model which acknowledges the effects of trauma on the entire family system and proposes that the healing of all parties (adults and children) occurs as a function of the bi-directional attachment between grandchild and grandparent(s).

Grandfamilies are a viable family constellation as diverse as the reasons for which they are formed and the individuals comprising them. Many grandparents and grandchildren are resilient and resourceful and their difficulty in adjusting to the grandfamily custodial arrangement can be considered minimal. However, some grandfamilies may require, and can benefit from, clinical intervention. The purpose of this paper is to increase therapist knowledge for providing clinical services to grandfamilies with young children formed in consequence of nuclear family trauma and/or abuse. Accordingly, basic information regarding grandfamilies will be presented along with a discussion of the impact of trauma and grandfamily formation on the grandchild(ren) and grandparent(s). An attachment-based model of family therapy is introduced and discussed with particular attention to how family therapy can be used to facilitate attachment healing. 


\section{Therapist knowledge regarding grandfamilies}

In the past, when a grandparent assumed the role of caregiver to dependent children it was as the result of a life event, such as death, divorce, or abandonment. Although these events still figure prominently in the assumption of caregiving by grandparents, there are several additional reasons, including parental drug dependence (Casper \& Bryson, 1998; Hayslip \& Kaminski, 2005a; Heywood, 1999; McGowen, Ladd, \& Strom, 2006; Pinson-Millburn, Fabian, Scholssberg, \& Pyle, 1996; Ross \& Aday, 2006). In this circumstance, not only are the grandparents dealing with the issues of having a child who is abusing drugs, but they are also faced with raising a grandchild who may be suffering serious developmental problems as a result of a parents' drug use (Pinson-Millburn et al., 1996).

Another common reason for the increase in grandparent-headed households is the decrease in two-parent households, from more than $86 \%$ in 1950 to about $70 \%$ of family constellations in the mid-1990s (Harden, Clark, \& Maguire, 1997). The third leading factor associated with the increase in grandfamilies is abuse and neglect of grandchildren perpetrated by one or both parents (Hayslip \& Kaminski, 2005a; McGowen et al., 2006; Pinson-Millburn et al., 1996). Closely related are the number of children who are placed with grandparents because of domestic violence and the associated risk for the children as witnesses to, or potential victims of, the violence (McGowen et al., 2006). Other reasons include the death, incarceration, or military service of a parent and mental health conditions of parents, which compromise their ability to take care of their children (McGowen et al., 2006; Ross \& Aday, 2006). These reasons, while not exhaustive, are the most common explanations for grandparents taking on the role of custodial grandparenting.

\subsection{Trauma and grandchildren}

A traumatic stressor for a child has been defined as, "direct experience, witnessing, or confrontation with an event or events that involve actual or threatened death or serious injury to the child or others, or a threat to the psychological or physical integrity of the child or others" (Zero to Three, 2005, p. 19). Given the aforementioned common antecedents to the formation of a grandfamily, it is important to assess for the impact of trauma experienced by the grandchild and the effects of removal from the nuclear family.

Research on the developmental impact of being raised by a custodial grandparent has been minimal. In fact, most of the studies on grandfamilies have focused on the effects of the grandchild's behavior, the requisite caregiving responsibilities, and accompanying stresses on the grandparent (Hayslip \& Kaminski, 2006). After an extensive search, only five studies (Dolbin-MacNab, 2005; Goodman, 2007; Keller \& Stricker, 2003; Leder, Grinstead, Jensen, \& Bond, 2003; Solomon \& Marx, 1995) were found that focused on outcomes in grandchildren being raised by a custodial grandparent. Because so few studies have used a distinct grandfamily sample, it becomes necessary to integrate research and information from related topics such as children who receive grandparental care (e.g., Fergusson, Maughan, \& Golding, 2008) and children in kinship foster care placements (e.g., Billing, Ehrle, \& Kortenkamp, 2002; Dubowitz et al., 1994; Dubowitz, Zuravin, Starr, Feigelman, \& Harrington, 1993) to highlight possible issues facing grandfamilies.

\subsubsection{Physical development}

Studies examining the physical well-being of children in grandfamilies and kinship care have produced mixed results. Comparing the health of children living in grandparent-headed families with that of children living in families with one or two biological parents, Solomon and Marx (1995) found that children in grandfamilies appeared to be healthier than children raised in the other family types. In contrast, a descriptive study by Silverstein and Vehvilainen (2000) found 35\% of custodial grandparents reporting that at least one of the grandchildren in their care had health problems. Asthma and chronic ear infections were reported as the most common health problems encountered.

Studies of children in kinship care suggest that children in grandfamilies may have an increased risk for poor physical health outcomes. Dubowitz et al. (1994) reviewed the medical records of 407 children in kinship care who came in for clinical assessment and concluded that, "compared to American children in general, children in kinship care appear to have many more health problems" (p. 94). For example, $7 \%$ more children in their sample failed hearing screenings than those in a national sample. They also found the rate of anemia and asthma to be higher than comparison children in national estimates. Billing et al. (2002) found 14\% of children living in kinship care to have a limiting condition and $7 \%$ were reported in fair or poor physical health. This is compared to $8 \%$ and $4 \%$ respectively of children living with a parent.

\subsubsection{Emotional development}

With regard to emotional development, studies have similarly yielded conflicting results. Solomon and Marx (1995) report that children raised solely by grandparents have fewer behavioral problems in school than children living with only one biological parent, whether single or remarried. However, in their sample of 346 children in kinship care, Dubowitz et al. (1993) found that $42 \%$ of boys and $28 \%$ of girls had behavioral problem scores in the clinical range, compared with an expected $10 \%$ in the general population. In a subsequent study of 524 children in kinship care, Dubowitz et al. (1994) reported that $26 \%$ of the children exhibited severe behavioral problems.

Other studies concluded that children in kinship care, including custodial grandchildren, are at increased risk for emotional problems and behavioral disorders (Billing et al, 2002; Leder et al, 2003) including attention deficit disorders, posttraumatic stress disorder, depression, and other psychiatric disorders such as developmental delays and anxiety disorders (Fergusson et al., 2008; Pinson-Millburn et al., 1996). Common behavioral problems for children in grandfamilies include excessive clinging, sleeping problems, eating problems, regressed behaviors, and limit-testing behaviors (Toledo \& Brown, 1995).

Contextualizing and/or influencing emotional development for children are the circumstances surrounding the necessity of placement with a grandparent. In fact, the circumstances precipitating a child's placement in a grandfamily can intensify the degree to which a child's emotional development is impacted. For example, sexual abuse victimization (by a parent) is more complicating and stigmatizing for the child than having to be placed in a grandparent's care because one's mother was pregnant as a teen. Another contextual issue is whether the parent(s) are deceased, because children may be experiencing grief and bereavement issues or shame and guilt, depending on the cause of death. Most children seek comfort and solace from attachment figures (i.e., parents) to facilitate the grieving process. In the case of custodial grandchildren, they may not have a stable or reliable attachment figure from whom they can seek comfort. In some instances, the placement in a grandparent's care is also accompanied by a geographical re-location, thereby removing children from their familiar support network of friends, neighbors, and teachers Complicating the grandparent's ability to support a grandchild may be the grandparent's own grief relative to the circumstances that necessitated the grandchild's placement. Furthermore, if a grandparent is not physically or emotionally available, the grandchild may feel alone in grief and harbor feelings of sadness, anger, guilt, regret, or anxiety (Hayslip \& Kaminski, 2006; Pinson-Millburn et al., 1996).

\subsubsection{Intellectual development}

Because school performance figures prominently in the development of children, custodial grandchildren's school experience and risk 
factors warrant review. Grandchildren in grandparent-headed families are similar to other children with respect to relationships with teachers. However, grandmothers were more likely to report that the grandchildren were average or below average students and grandchildren were more likely to have repeated a grade than children in two-parent families (Solomon \& Marx, 1995).

Sawyer and Dubowitz (1994) studied 372 school-age children in kinship care. Student mean scores on reading and math subtests were used to evaluate the sample of students in kinship care with a comparison group. For both reading and math subjects, children in kinship care scored significantly worse than children in the comparison group. They also found $30 \%$ of the children in their sample to be receiving special education services when the national special education placement rate was $10 \%$. Using data from the National Survey of America's Families (NSAF), Billing et al. (2002) found that $29 \%$ of children living in kinship care exhibited low levels of school engagement compared to $7 \%$ of children in parent care.

In summary, when working with custodial grandchildren, it is important to assess for the effects of any trauma. In addition, while the trauma itself will be a risk factor for normal functioning in the abovementioned areas, continued struggles in these domains will further complicate child development. Consequently, to help ensure increased emotional, physical, and academic development, it is important to assess for any delays in performance and address them accordingly in treatment.

\subsection{Trauma and grandparents}

Definitions of trauma for adults include the following specifications from the primary diagnostic manual used in the mental health professions (DSM-IV-TR):

Direct personal experience of an event that involves actual or threatened death or serious injury, or other threat to one's physical integrity; or witnessing an event that involves death, injury, or a threat to the physical integrity of another person; or learning about unexpected or violent death, serious harm, or threat of death or injury experienced by a family member or other close associate. (American Psychiatric Association, 2000, p. 463).

However, there is some ambiguity about what qualifies as a traumatic event and research suggests that the degree to which an event is considered traumatic is contingent upon trauma magnitude and a range of victim variables (Briere, 2004). Because there is no "typical" reaction to an event, that which is experienced as traumatic or distressing to one individual may not be traumatic or distressing to another. As such, it is important for clinicians to be knowledgeable about the positive experiences associated with caregiving as well as those negative aspects that may indicate symptoms related to distress and trauma.

\subsubsection{Grandparent positive experiences}

A study by McGowen et al. (2006) presents the positive experiences of grandmothers raising their grandchildren. Among their positive perceptions were that they were more patient, relaxed, less angry, less frustrated, and more concerned with their grandchildren's needs than they had been with their own children. They reported being able to spend more time enjoying the grandchildren and being more involved in their activities. Grandparents believed that caring for their grandchildren had enriched their lives and they were happier. They felt a renewed sense of purpose, more joy in their lives, and the grandchildren kept them more active and feeling younger. Finally, they felt that the rewards and blessings of caring for their grandchildren far outweighed any sacrifices they had to make.

Focus groups with African American grandparent caregivers identified companionship, devotion to grandchildren, and the oppor- tunity that caring for grandchildren gave them to "keep up with the times" as positive outcomes for custodial grandparenting (Baird, John, \& Hayslip, 2000). The grandparents also expressed relief at being able to keep the family together. Furthermore, they cited an increased confidence in their abilities to provide care for their grandchildren and a renewed sense of purpose as benefits to their role as a custodial grandparent.

Finally, Harrison, Richman, and Vittimberga (2000) compared the primary caregivers of 82 children exhibiting behavioral problems and found that parents from both single and two-parent families reported higher levels of parental stress than did grandparents. It was suggested that grandparents are better prepared due to their experience raising their own children and thus they have a lower severity of perceived parental stress.

\subsubsection{Grandparent negative experiences}

Being a grandparent who provides substantial care for a grandchild may have negative personal, interpersonal, economic, and legal consequences. Strawbridge, Wallhagen, Shema, and Kaplan (1997) compared the health of 42 grandparents caring for grandchildren, 44 spouses caring for a spouse, and 130 adult children caring for parents with 1669 non-caregivers in 1974 and again in 1994. At both times, grandparent caregivers were more likely to experience poorer physical and mental health than non-caregivers. Further, grandparent caregivers were significantly more likely than spouse care givers or adult children caring for parents to have experienced negative life events. These life events included such things as problems with marriages, finances, and physical health. Two studies have identified specific physical consequences of caregiving in grandparents. In a study of 54,412 women, Lee, Colditz, Berkman, and Kawachi (2003) identified an increased risk of coronary heart disease for women who were providing $9 \mathrm{~h}$ or more per week of caregiving for their grandchildren. In one-third of grandparents studied, Minkler, Roe, and Price (1992) noted observable declines in physical health after the grandparents began their caregiving role. For example, more than $51 \%$ of their sample complained of joint swelling and stiffness, $41 \%$ reported severe back problems, and 25\% cited heart trouble. Additionally, McGowen et al. (2006) found that grandmothers felt that raising their grandchild was tiring or had negatively affected their health.

The psychological and emotional consequences brought on by caregiving may be significant. As grandparents take on caregiving, they frequently do so at times of high stress and crisis or traumatic events. In some instances, as grandparents are gaining a grandchild they may be losing their own child. Pinson-Millburn et al. (1996) summarized the emotional response to these circumstances as one of grief-"grief for the loss of their children through death, addiction, unemployment, child neglect or abuse, or some other psychological or physical disability" (p. 551). Closely aligned with grief is the difficulty that grandparents may have in adjusting to a "time-disordered" role or a parenting duty that is out of sequence with their life cycle stage. As a further complication, the significance of the losses of custodial grandparents is not always acknowledged by society and may result in little social support for the custodial grandparenting role (Miltenberger, Hayslip, Harris, \& Kaminski, 2003-2004).

In regards to a specific indicator of individual well-being, depression has been found to be greater among grandparent caregivers than in non-caregiver peers (Goodman \& Silverstein, 2006; Kolomer \& McCallion, 2005; Minkler, Fuller-Thomson, Miller, \& Driver, 2000). In fact, grandparent caregivers had close to twice the rate of depression compared to non-caregiving grandparents $(25.1 \%$ versus 14.5\%; Minkler et al., 2000). Other significant emotional consequences for grandparents in this group include feelings of guilt, anxiety, hostility, rage, resentment, and shame (Hayslip \& Kaminski, 2005a; Heywood, 1999; Pinson-Millburn et al., 1996). Focusing specifically on African Americans, Crowther and Rodriguez 
(2003) found that custodial grandparents experienced negative psychological effects as a result of their role, while Ross and Aday (2006) found that the majority of grandparent caregivers were highly stressed, with $92 \%$ experiencing clinically significant levels of stress.

Interpersonal consequences of caregiving occur in terms of decreased socialization with friends and family (Hayslip \& Kaminski, 2005a; Heywood, 1999; McGowen et al., 2006; Pinson-Millburn et al., 1996). Contributing to the feelings of isolation are perceived losses in personal time and freedom (Baird et al., 2000; Kolomer \& McCallion, 2005; McGowen et al., 2006). Robinson and Wilks (2006) reported that an additional area of interpersonal difficulty for grandparent caregivers occurs in their relationship with their spouse. This was especially true if the spouse was not biologically related to the grandchild. Participants in their study reported that they once held the expectation of retiring and relaxing with their spouses and now there was a major disruption in the home as a result of their caretaking responsibilities.

Custodial grandparenting also brings financial consequences, including the costs associated with education, medical and dental care, housing, food, and clothing. Additionally, grandparents who are working need to pay for daycare (Heywood, 1999). To fully appreciate the financial burden that caretaking entails, it should be noted that many grandparents are on fixed incomes. In fact, $26 \%$ of custodial grandparents have been identified as living below the poverty level (Fuller-Thomson, Minkler, \& Driver, 1997).

Finally, legal problems are encountered by grandparents who have physical but not legal custody of their grandchildren. Enrolling a child in school and obtaining medical or dental care can be difficult for grandparents who do not have legal custody. Ehrle and Day (1994) point out that many custodial grandparents do not have the financial resources to pay the legal fees required to obtain custody. Also, many grandparents do not want to have to go to court to prove that their own child is an unfit parent.

\subsection{Attachment and grandfamilies}

The need to address attachment in grandfamilies has only recently been established by researchers (Cohen, Mannarino, Berliner, \& Deblinger, 2000; Dolbin-MacNab, 2005; Goodman, 2007; Keller \& Stricker, 2003). Poehlmann (2003), summarizing reviews by Greenberg (1999) and Lieberman and Zeanah (1999), maintains that an attachment perspective is especially valuable for furthering our understanding of grandfamilies. First, attachment theory is a conceptual framework that documents both the formation and disruption of dyadic relationships. As such, attachment theory examines the process associated with both adaptive and maladaptive relationship patterns. Second, it incorporates both a lifespan and intergenerational focus. Third, rather than focusing on one domain, attachment theory examines and considers interactions among behavioral, cognitive, emotional, interpersonal, and social-contextual dynamics in relationships. Fourth, since the genesis of attachment theory (Bowlby, 1969/1982), the effects of parental deprivation, separation, and loss on child development have been a central focus of attachment theory development. Using an attachment-based approach to treatment not only acknowledges these points, but also allows for the fact that the emerging attachment to a grandparent can mitigate the negative impact of trauma on children and improve their ability to resolve the effects of trauma (Cohen et al., 2000).

Bowlby (1969/1982) and Main and Goldwyn (1984) have posited that the quality of attachment-caregiving relationships may be transmitted from one generation to the next. This has both negative and positive implications when working with grandfamilies. Exploring the intergenerational nature of trauma and disrupted attachment, Keller and Stricker (2003) compared disrupted attachment between custodial grandchildren and their mothers to the attachment of the grandchild to the custodial grandparent. In their sample, of those children reporting non-optimal relatedness to mothers, $38 \%$ were classified as having confused relatedness to their custodial grandparent.

While Keller and Stricker's study is an example of a negative implication, Goodman (2007) found that grandchildren did well if they were able to attach and feel close to their grandmother, a positive implication. George and Solomon (1999) found that secure attachments were more easily transmitted from generation to generation than insecure relationships, which showed more variability and intergenerational discontinuity. Poehlmann (2003) summarizes George and Solomon by stating, "This is a positive finding because it indicates that security tends to replicate itself across generations, whereas insecurity is not automatically transmitted" (p. 160). However, as Poehlmann cautions, while insecure attachment relationships may not be automatically transferred across generations, the high risk factors such as substance abuse, maltreatment, and psychopathology associated with trauma and subsequent insecure attachment relationships do tend to run in families (e.g., Brook, Whiteman, \& Brook, 1999; Crittenden, 1996; Main \& Goldwyn, 1984; Osofsky \& Thompson, 2000).

Although risk factors have been found to run in families, individual family members follow unique developmental paths and have experiences that may either increase or decrease resiliency (Egeland, Jacobvitz, \& Sroufe, 1998; Werner, 2000). It is important for those working with grandfamilies to remember that, "A history of insecure attachment relationships does not necessitate repeating this pattern with subsequent generations, although it indicates a heightened risk for intergenerational patterns of maladaptive relationships" (Poehlman, 2003, p. 161). Recognizing this, professionals working with grandfamilies can and should facilitate experiences that will encourage secure attachment between custodial grandchildren and grandparents, thereby breaking intergenerational patterns of relationship dysfunction.

Dolbin-MacNab (2005) found that grandparents who reported they were not bonded to their grandchildren perceived their grandchildren as having difficulties with affect regulation. Poor affect regulation, defined as compromises in emotion regulation and lability-negativity was tied to perceived behavioral problems and poorer family functioning. An unexpected finding of Dolbin-MacNab was that grandchildren who were attached to their grandparents were reported by their grandparents as having more behavioral problems. One reason for this may be that perhaps the grandchildren who are more attached believe they do not have to "hide" from their grandparents. Instead they can be open with their feelings and behaviors. Knowledge of this finding would permit therapists and grandparents to reframe a grandchild's negative behavior into a positive reflection of the emerging attachment relationship.

To summarize, when treating grandfamilies, knowledge of the unique characteristics of grandfamilies is important. It is prudent to remember that grandfamilies are diverse and complex and contextual factors including gender, ethnicity, social support and the availability of support services must always be considered. As with nuclear families, some thrive and adjust to circumstances while others, for a plethora of reasons, do not fare as well. For children, a separation from a parent for an extended period of time for any reason has the potential to be traumatic (Bowlby, 1969/1982). Integrating the effects of trauma with attachment theory provides a theoretical framework with which to conceptualize the symptoms present in a grandfamily. The following model proposes that healing is facilitated within the emerging attachment relationship of the grandchild with the custodial grandparent. Furthermore, family therapy is a critical intervention when working with grandfamilies to address attachment needs of all members of the grandfamily.

\section{Attachment-based family therapy model}

This model applies specifically to grandfamilies where the grandparents are custodial grandparents and are the primary caregivers of 
the grandchild (see Fig. 1). The model illustrates the healing of trauma-related injuries occurring within the grandparent/grandchild relationship as emerging attachment is facilitated through developmentally appropriate family therapy interventions. Inherent in this model is the assumption that trauma produces negative effects on the bio-psychosocial development of the grandparent and the grandchild. Trauma effects are represented separately for the grandparent and grandchild because, although the events leading to the creation of a grandfamily are the same for both the grandparent and the grandchild, the trauma associated with the events will be experienced differently. This is observable most clearly in the fact that trauma results in a disrupted attachment between the parent and the child and between the parent and the child's grandparent.

With the formation of a grandfamily comes the opportunity to heal attachment injuries through the emerging attachment between the grandchild and the grandparent(s). It is important to remember that the development of strong, secure attachments will not only lead to greater health for the grandchild, but will also facilitate healing for the grandparent. As both grandchild and grandparent experience new ways of relating to each other via family therapy, their internal working models will begin to shift and attachment will be facilitated.

This model is most applicable to treatment in situations where grandparents become sole caretakers of their grandchild and the biological parent has little to no contact with the child. In many instances, however, there is a possibility that the parent will continue to be a part of the child's life. Accordingly, the parent's role in the system is diminished (illustrated by a dashed circle, post-treatment), highlighting the likelihood that both the grandparent and the grandchild will re-define the role of the parent in their respective lives and that the primary attachment bond will be found in the grandparent-grandchild relationship.

Historically, treatment of grandfamilies involved individual treatment for the grandparent and the grandchild, with grandparents often referred to support groups (Cox, 2000; Smith, 2003) or parenting training (Kern, 2003). With advances in both trauma and attachment research, treatment models became more systemic and the grandparent/grandchild dyad began to receive attention, mostly within the context of improving grandchild behaviors (Bratton, Ray, \& Moffit,
1998; Lieberman \& Van Horn, 2008; VanFleet, 2005). The treatment model presented here is designed to take intervention a step further. This model shifts the focus from parenting skills to one of increasing the grandparent's attachment to the grandchild (as detailed in DolbinMacNab, 2005), as well as, strengthening the grandchild's attachment to the grandparent with an emphasis on moderating the effects of trauma. This model purposefully blends the systemic tenets of family therapy (e.g., involving the entire grandfamily system in session) with play therapy (thereby considering the developmental needs of young children) while facilitating stronger relationships through playful and healthy grandparent/grandchild interactions and attachment experiences.

With regards to integrating attachment theory with family systems theory, Kozlowska and Hanney (2002) make two points that are particularly salient to working with grandfamilies. First, while attachment is traditionally viewed within a dyadic relationship, dyadic relationships are subsystems of a family system. Family systems theory maintains that subsystems affect other subsystems. In other words, each part or subsystem forms a whole, but each subsystem is also a part of a greater whole. This concept has particular relevancy when conceptualizing the former attachment relationships between grandparent and parent and parent and child. With the formation of a grandfamily, these former attachment relationships will shift and new bi-directional attachment relationships between grandparent(s) and grandchild(ren) will emerge. By integrating attachment theory with family systems theory, the clinician is able to navigate between system levels (i.e., between a specific grandparent/child dyad to a view of how each grandparent/grandchild subsystem affects the rest of the system). Observing both process and content during family sessions allows clinicians to intervene and to provide experiences for the family that will strengthen emerging attachments between all family members.

Secondly, Kozlowska and Hanney (2002) emphasize that all attachment strategies are seen as adaptations to a particular relationship. Children's behaviors and mental strategies are seen as biologically driven and as purposeful and necessary for safety and survival. The development of symptoms and behaviors are best understood in light of their adaptive function. While family therapists

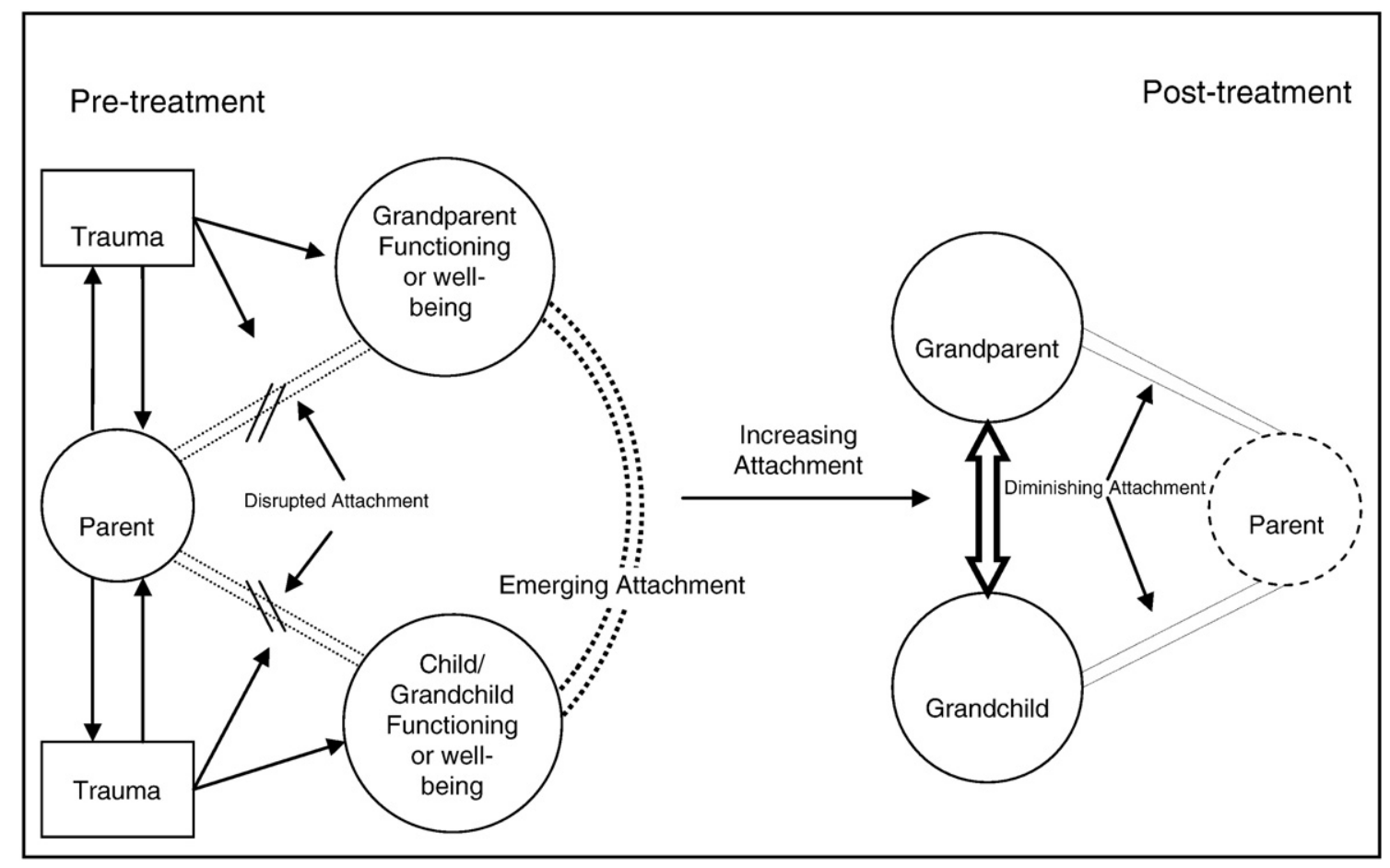

Fig. 1. Fostering healing in grandfamilies through attachment. 
have similarly tracked the function of a child's behavior, attachment theory further informs case conceptualization by adding the evolutionary underpinnings. When working with a grandfamily this is important because it allows the behaviors of family members to be viewed as strengths and strategies used to cope with complex situations rather than weaknesses or deficits.

A family systems model is especially appropriate for this population because of the premise that attachment issues are best addressed within a relationship context. In other words, relationships are central to shaping personality development in children and as such, effective intervention for emotional and social difficulties should focus on the attachment-caregiving system (Lieberman \& Van Horn, 2008). It is important to remember that the ability and willingness of the grandparents to attune to developmental and other needs will affect the child's ability to form a secure attachment with the grandparent (Connor, 2006). This attunement or "dance" (Marvin, 2003) is best addressed in a family therapy setting, where the attunement can be observed and interventions delivered when indicated. Although trauma negatively impacts attachment and internal working models, intervention focusing on the emerging grandfamily attachments facilitates the healing of attachment wounds for both grandparent(s) and grandchild(ren). As conceptualized here, this then allows attachment to moderate the effects of trauma, thereby increasing the wellbeing of all grandfamily members.

\section{Conclusion}

Census data and studies have confirmed that the number of caregiving grandparents and, more specifically, grandfamilies, are increasing. Understanding precipitating factors that lead to caregiving, as well as how caregiving impacts the caregivers, helps to prepare therapists to provide effective services and interventions. Custodial grandchildren must adjust to new caregivers, possibly a new physical living arrangement, school, and friends, and losses of other support systems. Grandparents also must adjust to the additional demands of custodial caregiving and the consequences, both positive and negative, of those demands.

In order to deliver therapeutic services tailored to the circumstance of the grandfamily constellation, two points must be considered. First, clinicians must understand the common traumas and precipitating factors associated with their formation. It is important to note that the factors presented above and the subsequent developmental impact of these factors, on both the grandchild(ren) and the grandparent(s), are generalizations. Although based on empirical research (qualitative and quantitative), these identified generalizations and characteristics may or may not apply to a particular grandfamily. Second, it is difficult to discriminate between problems stemming from factors leading to kinship care and those brought about or intensified by being raised by a grandparent (Walter, 2003). Both the trauma leading to kinship care with its ensuing attachment disruption and placement in a grandfamily have the potential to significantly influence multiple facets of a grandchild's development. Therefore, clinicians must continually assess and look for clinical evidence to confirm the application of general principles and characteristics to a particular grandfamily.

Further, acknowledging and treating the effects of trauma leading to the formation of a grandfamily is necessary, but not sufficient. The attachment disruptions resulting from the trauma must also be a focus of treatment. The model presented proposes that healing is facilitated within the bi-directional emerging attachment relationship between the grandchild and the grandparent. Family therapy is advocated as an appropriate intervention that acknowledges the importance of a systems perspective of attachment as well as providing a method of treatment that allows attachment relationships to be observed and interventions delivered in a salient manner.

When working with grandfamilies, interventions that target both grandparent caregivers and grandchildren within a family therapy model may be the most effective. Sadly, minimal research has been done on the effects on grandchildren of being raised in a grandfamily and we know little about the consequences in adulthood of having been raised by a custodial grandparent. The long-term consequences of being a custodial grandparent are also unknown (Hayslip \& Kaminski, 2005b). Cultural variations among custodial grandparents also warrant investigation (Toledo, Hayslip, Emick, Toledo, \& Henderson, 2000).

Finally, much of what has been written about working with grandfamilies has been taken from the fields of trauma, attachment, foster care, kinship care, and adoption, assuming that the pertinent information is relevant to grandfamilies. Research specific to family system-related processes in grandfamilies is needed. As part of that research, attention to the emerging attachment process between grandchild and grandparent is warranted.

\section{References}

American Psychiatric Association (2000). Diagnostic and statistical manual of mental disorders-Text revision (4th ed.). Washington, DC: Author.

Baird, A., John, R., \& Hayslip, B. (2000). Custodial grandparenting among African Americans: A focus group perspective. In B. Hayslip Jr. \& R. G. Glen (Eds.), Grandparents raising grandchildren: Theoretical, empirical, and clinical perspectives (pp. 125-144). New York: Springer Publishing.

Billing, A., Ehrle, J., \& Kortenkamp, K. (2002). Children cared for by relatives: What do we know about their well-being? (Series B., No. B-46. Washington DC: Urban Institute.

Bowlby, J. (1969/1982). Attachment and loss: Vol.1. Attachment. New York: Basic Books.

Bratton, S., Ray, D., \& Moffit, K. (1998). Filial/family play therapy: An intervention for custodial grandparents and their grandchildren. Educational Gerontology, 24, $391-406$.

Briere, J. (2004). Psychological assessment of adult posttraumatic states: Phenomenology, diagnosis, and measurement (2nd ed.). Washington, DC: American Psychological Association.

Brook, J. S., Whiteman, M., \& Brook, D. W. (1999). Transmission of risk factors across three generations. Psychological Reports, 85, 227-241.

Busch, A. L., \& Lieberman, A. F. (2007). Attachment and trauma: An integrated approach to treating young children exposed to family violence. In D. Oppenheim \& D. F. Goldsmith (Eds.), Attachment theory in clinical work with children: Bridging the gap between research and practice (pp. 139-171). New York: Guilford Press.

Casper, L. M., \& Bryson, K. R. (1998). Co-resident grandparents and their grandchildren: Grandparent maintained families. Annual meeting of the Population Association of America, Chicago Retrieved [date] from www.census.gov/population/www/documentation/ twps0026/twps0026.html

Cohen, J. A., Mannarino, A. P., Berliner, L., \& Deblinger, E. (2000). Trauma-focused cognitive behavioral therapy for children and adolescents: An empirical update. Journal of Interpersonal Violence, 15, 1202-1223.

Connor, S. (2006). Grandparents raising grandchildren: Formation, disruption and intergenerational transmission of attachment. Australian Social Work, 59, 172-184.

Cox, C. B. (2000). Empowering grandparents raising grandchildren: A training manual for group leaders. New York: Springer.

Crittenden, P. M. (1996). Research on maltreating families: Implications for intervention. In J. Briere \& L. Berliner (Eds.), The APSAC handbook on child maltreatment (pp. 158-174). Thousand Oaks, CA: Sage.

Crowther, M., \& Rodriguez, R. (2003). A stress and coping model of custodial grandparenting among African Americans. In B. Hayslip Jr. \& J. H. Patrick (Eds.), Working with custodial grandparents (pp. 145-162). New York: Springer Publishing Co.

Dolbin-MacNab, M. L. (2005). Grandchild adjustment and family functioning in grandparent-headed families: The role of attachment relationships (Doctoral thesis, Purdue University, 2004). Dissertation Abstracts International, 65(11-A), 4362.

Dubowitz, H., Zuravin, S., Starr, R. H., Feigelman, S., \& Harrington, D. (1993). Behavior problems of children in kinship care. Journal of Developmental and Behavioral Pediatrics, 14, 386-393.

Dubowitz, H., Feigelman, S., Harrington, D., Starr, R., Zuravin, S., \& Sawyer, R. (1994). Children in kinship care: How do they fare? Children and Youth Services Review, 16, $85-106$.

Edwards, T. (2009, February 25). As baby boomers age, fewer families have children under 18 at home. U.S. Census Bureau News Retrieved from http://www.census.gov/ Press-Release/www/releases/archives/families_households/013378.html

Edwards, O. W., \& Daire, A. P. (2006). School-age children raised by their grandparents: Problems and solutions. Journal of Instructional Psychology, 33, 113-119.

Edwards, O. W., \& Sweeney, A. E. (2007). Theory-based interventions for school children cared for by their grandparents. Educational Psychology in Practice, 23, 177-190.

Egeland, B., Jacobvitz, D., \& Sroufe, L. A. (1998). Breaking the cycle of abuse. Child Development, 59, 1080-1088.

Ehrle, G. M., \& Day, H. D. (1994). Adjustment and family functioning of grandparents raising grandchildren in the United States. Gerontologist, 37, 406-411.

Fergusson, E., Maughan, B., \& Golding, J. (2008). Which children receive grandparental care and what effect does it have? Journal of Child Psychology and Psychiatry, 49, $161-169$. 
Fuller-Thomson, E., Minkler, M., \& Driver, D. (1997). A profile of grandparents raising grandchildren in the United States. Gerontologist, 37, 406-411.

George, C., \& Solomon, J. (1999). Attachment and caregiving: The caregiving behavioral system. In J. Cassidy \& P. R. Shaver (Eds.), Handbook of attachment: Theory, research, and clinical applications (pp. 649-670). New York: Guilford.

Goodman, C. C. (2007). Intergenerational triads in skipped-generation grandfamilies. International Journal of Aging and Human Development, 65, 231-258.

Goodman, C. C., \& Silverstein, M. (2006). Grandmothers raising grandchildren: Ethnic and racial differences in well-being among custodial and coparenting families. Journal of Family Issues, 27(1), 1605-1626.

Greenberg, M. T. (1999). Attachment and psychopathology in childhood. In J. Cassidy \& P. R. Shaver (Eds.), Handbook of attachment: Theory, research, and clinical applications (pp. 469-496). New York: Guilford.

Harden, A. W., Clark, R. L., \& Maguire, K. (1997). Informal and formal kinship care. Washington, DC: U.S. Department of Health and Human Services.

Harrison, K. A., Richman, G. S., \& Vittimberga, G. L. (2000). Parental stress in grandparents versus parents raising children with behavior problems. Journal of Family Issues, 21, 262-270.

Hayslip, B., \& Kaminski, P. L. (2005). Grandparents raising their grandchildren: A review of the literature and suggestions for practice. Gerontologist, 45, 262-269.

Hayslip, B., \& Kaminski, P. L. (2005). Grandparents raising their grandchildren. Marriage E' Family Review, 37, 147-160.

Hayslip, B., \& Kaminski, P. L. (2006). Custodial grandchildren. In G. G. Bear \& K. M. Minke (Eds.), Children's needs III: Development, prevention, and intervention (pp. 771-783). Washington, DC: National Association of School Psychologists.

Hayslip, B., \& Shore, R. J. (2000). Custodial grandparenting and mental health services. Journal of Mental Health and Aging, 6, 367-383.

Heywood, E. M. (1999). Custodial grandparents and their grandchildren. Family Journal: Counseling and Therapy for Couples and Families, 7, 367-372.

Keller, S., \& Stricker, G. (2003). Links between custodial grandparents and the psychological adaptation of grandchildren. In B. Hayslip Jr. \& J. H. Patrick (Eds.), Working with custodial grandparents (pp. 27-43). New York: Springer.

Kern, C. W. (2003). Grandparents who are parenting again: Building parenting skills. In B. Hayslip Jr. \& J. H. Patrick (Eds.), Working with custodial grandparents (pp. 179-194). New York: Springer.

Kolomer, S. R., \& McCallion, P. (2005). Depression and caregiver mastery in grandfathers caring for their grandchildren. International Journal of Aging $\mathcal{E}$ Human Development, $60,283-294$.

Kozlowska, K., \& Hanney, L. (2002). The network perspective: An integration of attachment and family systems theories. Family Process, 41, 285-312.

Leder, S., Grinstead, L. N., Jensen, S., \& Bond, L. (2003). Psychotherapeutic treatment outcomes in grandparent-raised children. Journal of Child and Adolescent Psychiatric Nursing, 16, 5-14.

Lee, S., Colditz, G., Berkman, L., \& Kawachi, I. (2003). Caregiving to children and grandchildren and risk of coronary heart disease in women. American Journal of Public Health, 93, 1939-1944.

Lieberman, A. F., \& Van Horn, P. (2008). Psychotherapy with infants and young children: Repairing the effects of stress and trauma on early attachment. New York: Guilford Press.

Lieberman, A. F., \& Zeanah, C. H. (1999). Contributions of attachment theory to infantparent psychotherapy and other interventions with infants and young children. In J. Cassidy \& P. R. Shaver (Eds.), Handbook of attachment: Theory, research, and clinical applications (pp. 555-574). New York: Guilford.

Main, M., \& Goldwyn, R. (1984). Predicting rejection of her infant from mother's representation of her own experience: Implications for the abused-abusing intergenerational cycle. Child Abuse E' Neglect, 8, 203-217.

Marvin, R. S. (2003). Implications of attachment research for the field of family therapy. In P. Erdman \& T. Caffery (Eds.), Attachment and family systems: Conceptual, empirical, and therapeutic relatedness (pp. 3-27). New York: Brunner-Routledge.

McGowen, M. R., Ladd, L., \& Strom, R. D. (2006). On-line assessment of grandmother experience in raising grandchildren. Educational Gerontology, 32, 669-684.
Miltenberger, P. B., Hayslip, B., Harris, B., \& Kaminski, P. L. (2003-2004). Perceptions of the losses experienced by custodial grandmothers. Omega, 48, 245-261.

Minkler, M., Roe, K. M., \& Price, M. (1992). The physical and emotional health of grandmothers raising grandchildren in the crack cocaine epidemic. Gerontologist, 32, 5752-5761.

Minkler, M., Fuller-Thomson, E., Miller, D., \& Driver, D. (2000). Grandparent caregiving and depression. In B. Hayslip Jr. \& R. G. Glen (Eds.), Grandparents raising grandchildren: Theoretical, empirical, and clinical perspectives (pp. 207-219). New York: Springer Publishing.

Osofsky, J. D., \& Thompson, M. D. (2000). Adaptive and maladaptive parenting: Perspectives on risk and protective factors. In J. P. Shonkoff \& S. J. Meisels (Eds.) Handbook of early childhood intervention (pp. 54-75). (2nd ed.). New York: Cambridge University Press.

Pinson-Millburn, N. M., Fabian, E. S., Scholssberg, N. K., \& Pyle, M. (1996). Grandparents raising grandchildren. Journal of Counseling \& Development, 74(6), 548-554.

Poehlmann, J. (2003). An attachment perspective on grandparents raising their very young grandchildren: Implications for intervention and research. Infant Mental Health Journal, 24, 149-173.

Robinson, M. M., \& Wilks, S. E. (2006). 'Older but not wiser': What custodial grandparents want to tell social workers about raising grandchildren. Social Work E' Christianity, 33, 164-177.

Ross, M. E. T., \& Aday, L. A. (2006). Stress and coping in African American grandparents who are raising their grandchildren. Journal of Family Issues, 27, 912-932.

Sawyer, R. J., \& Dubowitz, H. (1994). School performance of children in kinship care Child Abuse \& Neglect, 18, 587-597.

Silverstein, N. M., \& Vehvilainen, L. (2000). Grandparents and schools: Issues and potential challenges. In C. B. Cox (Ed.), To grandmother's house we go and stay: Perspectives on custodial grandparents (pp. 268-282). New York: Springer.

Smith, G. C. (2003). How caregiving grandparents view support groups: An exploratory study. In B. Hayslip Jr. \& J. H. Patrick (Eds.), Working with custodial grandparents (pp. 69-92). New York: Springer.

Solomon, J. C., \& Marx, J. (1995). "To grandmother's house we go": Health and school adjustment of children raised solely by grandparents. Gerontologist, 35, 386-394.

Strawbridge, W. J., Wallhagen, M. I., Shema, S. J., \& Kaplan, G. A. (1997). New burdens or more of the same? Comparing grandparent, spouse, and adult-child caregivers. Gerontologist, 37, 505-510.

Strom, R., \& Strom, S. (2000). Goals for grandparent caregivers and support groups. In B. Hayslip Jr. \& R. Goldberg-Glen (Eds.), Grandparents raising grandchildren: Theoretical, empirical, and clinical perspectives (pp. 171-218). New York: Springer.

Toledo, S., \& Brown, D. E. (1995). Grandparents as parents: A survival guide for raising a second family. New York: Guilford.

Toledo, R., Hayslip, B., Emick, M., Toledo, C., \& Henderson, C. (2000). Cross-cultural differences in custodial grandparenting. In B. Hayslip \& R. Goldberg-Glen (Eds.) Grandparents raising grandchildren: Theoretical, empirical and clinical perspectives (pp. 107-124). New York: Springer.

VanFleet, R. (2005). Filial therapy: Strengthening parent-child relationships through play (2nd ed.). Sarasota, FL: Professional Resource Press.

Walter, A. E. (2003). Passing on family stories: Family therapy with grandparents raising grandchildren. (Doctoral Dissertation, The Wright Institute, U.S.). Dissertation Abstracts International. B. The Sciences and Engineering, 64(3-B), 1512.

Werner, E. E. (2000). Protective factors and individual resilience. In J. P. Shonkoff \& S. J Meisels (Eds.), Handbook of early childhood intervention (pp. 115-132). (2nd ed.). New York: Cambridge University Press.

Whitley, D. M., White, K. R., Kelley, S. J., \& Yorke, B. (1999). Strengths-based case management: The application to grandparents raising grandchildren. Families in Society, $80,110-119$.

Zero to Three/National Center for Clinical Infant Programs (2005). Diagnostic classification of mental health and developmental disorders of infancy and early childhood, rev. ed. Washington, DC: Author. 